\title{
Design and Evaluation of Automated System Modules for Portable Programmable Logic Controller (PLC) Kit for Industrial Automation and Control Education
}

\section{Dr. Sheng-Jen "Tony" Hsieh, Texas A\&M University}

Dr. Sheng-Jen ('Tony") Hsieh is a Professor in the Dwight Look College of Engineering at Texas A\&M University. He holds a joint appointment with the Department of Engineering Technology and the Department of Mechanical Engineering. His research interests include engineering education, cognitive task analysis, automation, robotics and control, intelligent manufacturing system design, and micro/nano manufacturing. He is also the Director of the Rockwell Automation laboratory at Texas A\&M University, a state-of-the-art facility for education and research in the areas of automation, control, and automated system integration. 


\title{
Design and Evaluation of Automated System Modules for Portable Programmable Logic Controller (PLC) Kit for Industrial Automation and Control Education
}

\begin{abstract}
Automation impacts our lives on a daily basis. Automated doors, elevators, coffee makers, air conditioners, and copy machines all have controllers and sensors integrated into the machine to form an automated system that provides a service. Designing, building, and maintaining industrial scale automated systems is a complex and challenging task. Student education in this area is hindered due to lack of industrial scale equipment to demonstrate how these systems work and how they are integrated. This paper describes the design and evaluation of an automated system module that includes an industrial-scale controller and how this module has been integrated with a portable programmable logic controller (PLC) kit to make learning about automated systems and PLCs convenient and accessible in the classroom and at home. Responses from students suggest that (1) integrating the automated system module with a PLC kit for use in the classroom keeps them engaged in class and allows them to ask what-if questions, and (2) incorporating different kinds of automated system modules is beneficial. Future directions may include incorporating building an automated system module into course requirements, such as semester project.
\end{abstract}

\section{Motivation}

Across the five major industry groups that employ more than 40 percent of all manufacturing employees, nearly three out of every four plants use advanced manufacturing technology [1]. According to U.S. Census Bureau reports, in 2015, the U.S. exported \$16.04 billion in advanced technology products in the flexible manufacturing category - up 3.3\% from \$15.5 billion in 2014 and \$14.5 billion in 2013 [2-3]. This trend is likely to continue to increase as the manufacturing sector continues to transform to a high tech, less labor-intensive and value added industry using advanced automated systems. However, skilled engineers who can operate, maintain, design and build such systems are increasingly difficult to find, even though industrial automation jobs tend to pay well than other professionals [4-6].

Hsieh [7] surveyed 150 industry partners on skill sets needed for careers in industrial automation. Of these, 78 responded that their companies employ technicians or engineers who maintain automated manufacturing systems as part of their job. Of these 78 participants, the majority (about 88\%) indicated that their primary market segment/industry includes one of the following: oil \& gas, automotive, semiconductor \& electronics, energy storage and distribution, metals, or machine builder. Almost half (47\%) indicated that their job level was manager or above; the rest were primarily either engineers or technicians. The most commonly reported challenge by farnoted by over half of the respondents - was recruiting and retaining skilled technicians and engineers. Difficult-to-find skills included programmable logic control programming, system integration and automation, wireless technology, troubleshooting, welding, and fabrication. Several respondents commented that new hires need to be able to use PLCs; experience with hobbyist kits such as Arduino is not sufficient. Table 1 below compares Arduino with Micrologix 1000, which is a small PLC that can be used for industry applications [8, 9]. 
Table 1. Comparison of Arduino with MicroLogix 1000 Series PLC

\begin{tabular}{|c|c|c|}
\hline & Arduino & MicroLogix 1000 \\
\hline Cost & Low: around $\$ 20-\$ 40$ & High: around $\$ 500-\$ 700$ \\
\hline Operating voltage & $3.3 \mathrm{~V}, 5 \mathrm{~V}$ & $24 \mathrm{~V}, 110 \mathrm{~V}$ \\
\hline $\begin{array}{l}\text { Programming } \\
\text { language }\end{array}$ & $\mathrm{C} / \mathrm{C}++$ & Ladder logic \\
\hline Application & $\begin{array}{l}\text { Amateur. } \\
\text { Can be used for hobby or } \\
\text { small scientific projects for } \\
\text { quick deployment }\end{array}$ & $\begin{array}{l}\text { Industrial } \\
\text { Focus is on industry-level } \\
\text { I/O manipulation }\end{array}$ \\
\hline Flexibility & High & Moderate \\
\hline Reliability & Moderate & High \\
\hline Other & $\begin{array}{l}\text { Can accomplish complex } \\
\text { logic and programs; but } \\
\text { can lead to unexpected or } \\
\text { unstable results } \\
\text { C language is more } \\
\text { versatile }\end{array}$ & 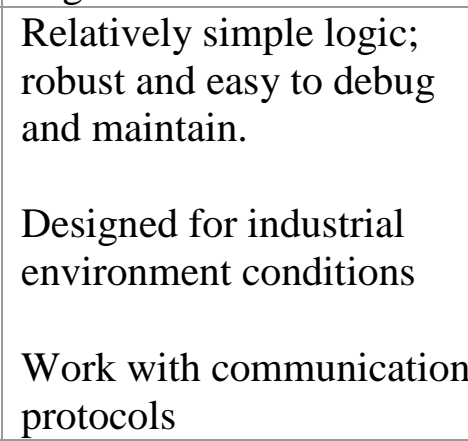 \\
\hline
\end{tabular}

A programmable logic controller (PLC) and Input/Output (I/O) devices such as motors, conveyers, actuators, and robot arms are the integrated components of every automated and semi-automated manufacturing system. At the heart of an automated system is the PLC, which makes process automation possible by orchestrating and synchronizing processes thru I/O devices to ensure that every activity happens in a controlled and coordinated manner. Although programmable logic controllers are not large devices, once the I/O devices and processing machines are connected to PLCs to form an automated system, the system can be bulky and expensive. As a result, student access to hands-on PLC and automated system education is heavily dependent on lab and equipment availability.

One approach to alleviating limitations in equipment availability is to make PLC and automation education portable and/or virtual. For example, LogixPro (http://www.thelearningpit.com/) employs animated educational simulations of processes, such as traffic control and batch mixing, to show how a ladder diagram relates to an automated process. Students can start and stop the animations, and study the corresponding ladder diagram for certain conditions or cases. In addition, Hsieh has developed an Integrated Virtual Learning System for Programmable Logic Controller (Virtual PLC). This web-based system uses a combination of animations, simulations, intelligent tutoring system technology, and games to teach about programmable logic controllers [10-12]. Both of these systems are good examples of how technology can be used to help students learn simple PLC programming concepts. However, for learning to write complex programs and building an automated system, there is no good substitute for hands-on experience programming a real PLC and a real automated system. 
Hsieh [13-14] describes the construction and evaluation of a low-cost portable PLC kit consisting of a controller module and special function modules. The controller module contains an industrial programmable logic controller and power supply unit. The special function modules includes (1) basic I/O module, (2) sensor module, and (3) automated systems module. Figure 1 includes a diagram and photo of the layout of a PLC kit with a basic I/O module. This paper describes the design and evaluation of an automated system module (that includes an industrial-scale controller) and how this module has been integrated with a portable PLC kit to make learning about automated systems and PLCs convenient and accessible inside and outside of the classroom. Figures 2 and 3 show examples of Portable PLC Kits with an automated system module.
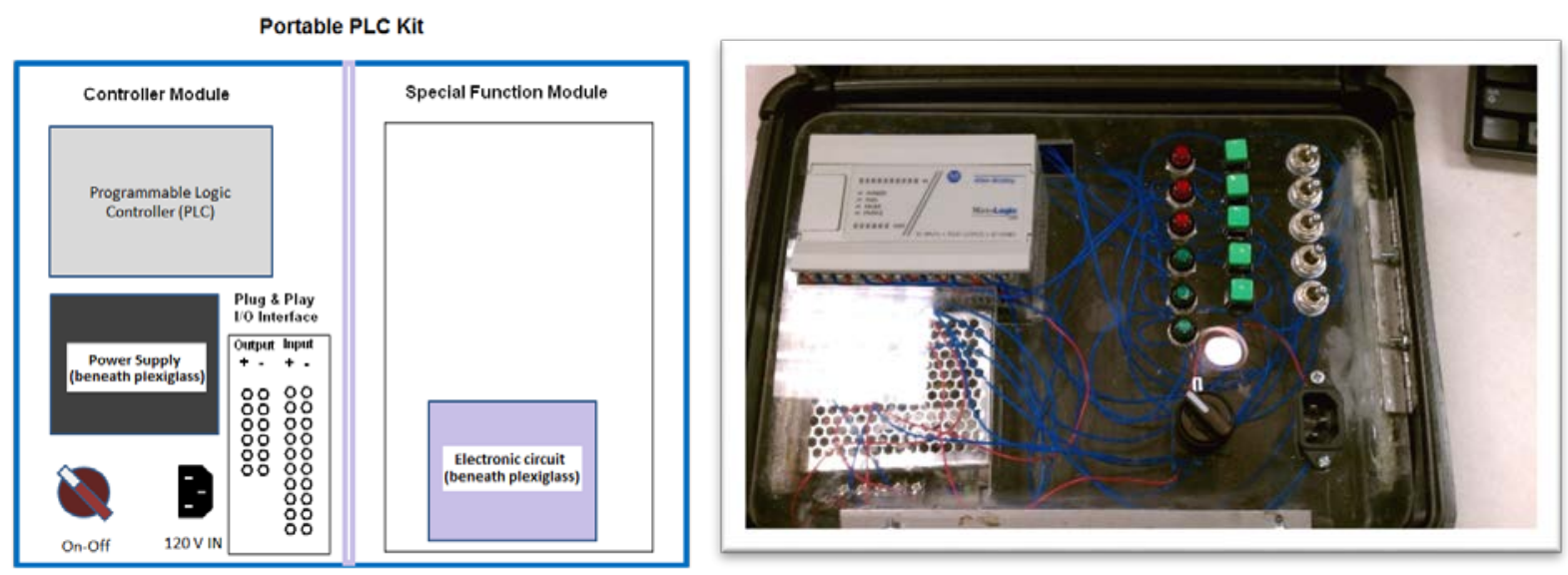

Figure 1. Diagram and Photo of Portable PLC Kit Layout (Basic I/O Module).

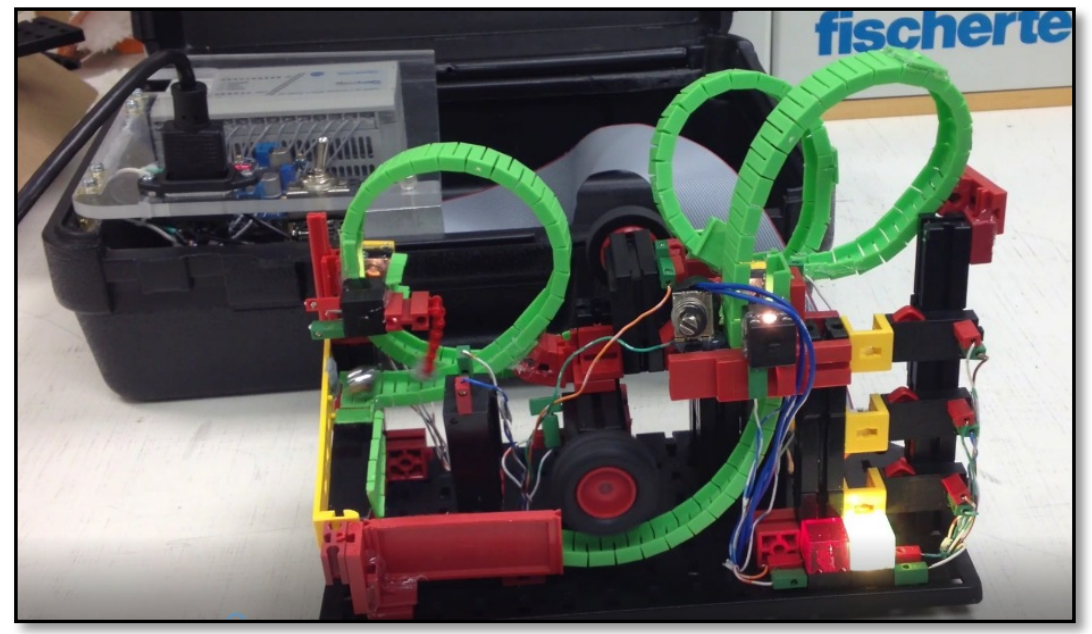

Figure 2. Portable PLC Kit with Automated System (Roller Coaster). 

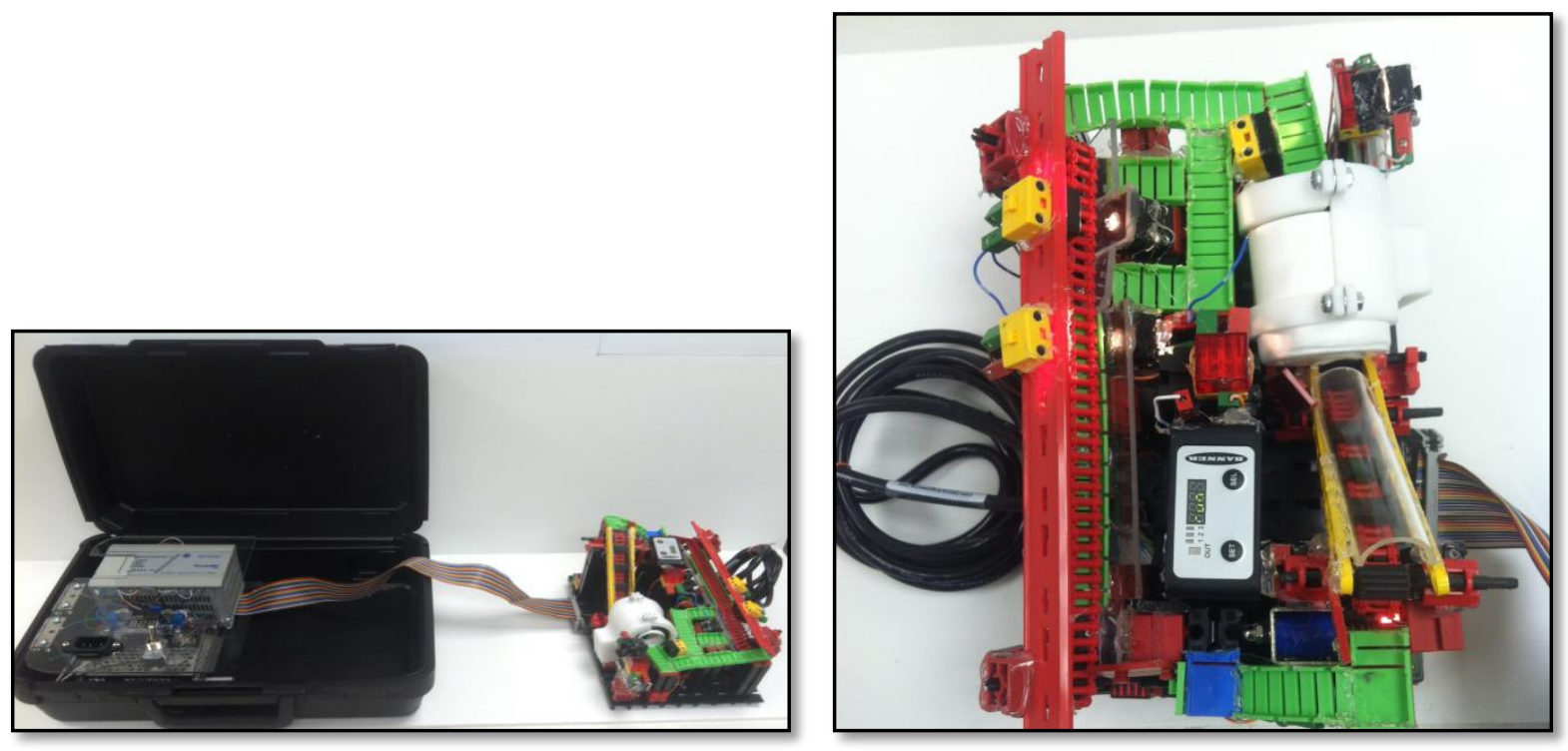

Figure 3. Portable PLC Kit with Automated System(Marble Sorting Machine).

\section{Case Studies}

Six teams of undergraduate students built Portable PLC kits with automated systems as part of a manufacturing automation and robotics course in Fall 2016. Students were introduced to the concept of an automated system and how components are integrated on the first day of the class through animations and videos of automated systems built by previous stduents and industry system integrators. Figure 4 show an animation of an automated system including all the necessary system components.

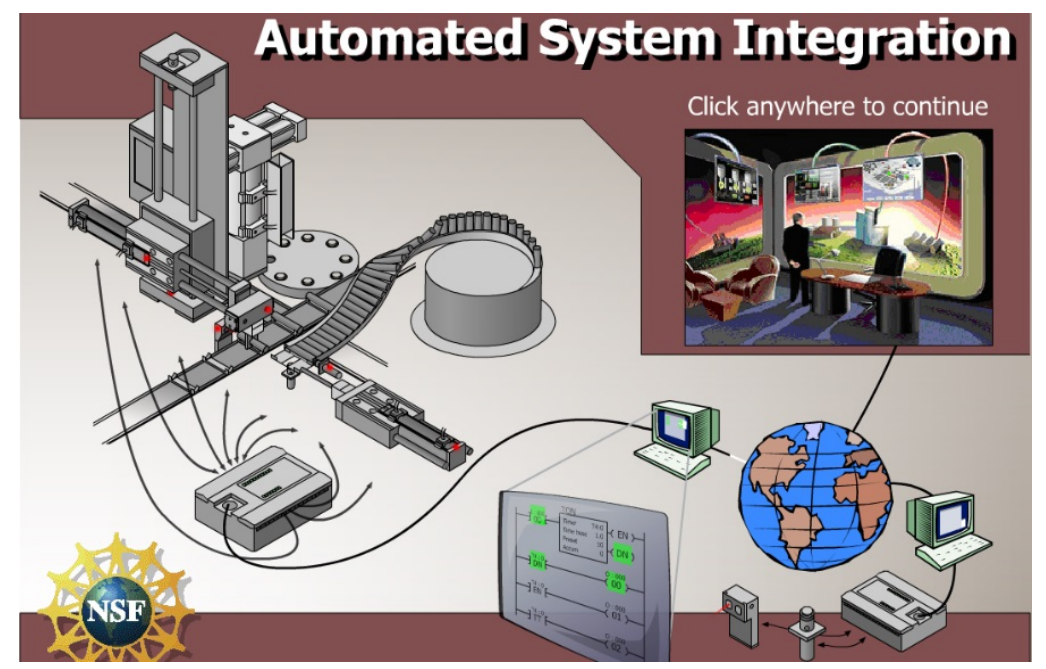

Figure 4. Animation illustrating Automated System Integration

\section{Automated System for Car Wash}

This system mimics a real-life car washing system. The system consists of three stations: spraying bubble station, washing station, and drying station. All these stations and a conveyor 
system are synchronized by a programmable logic controller (PLC). Figure 5 shows the entire automated system.

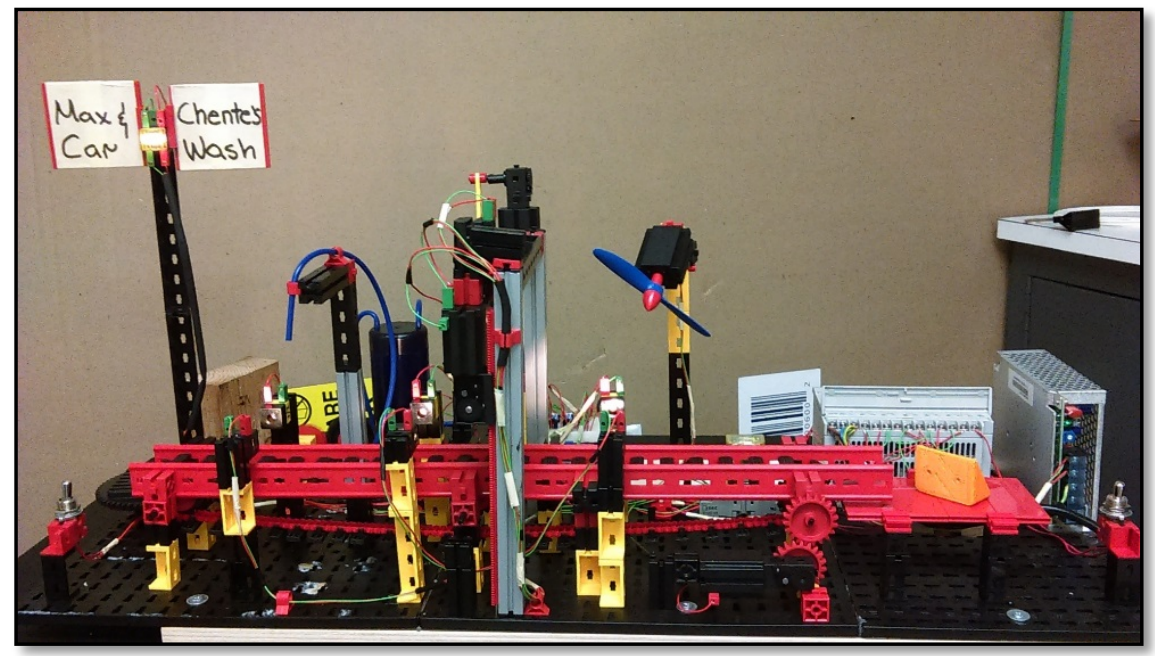

Figure 5. Overall Automated System for Car Wash Process.

\section{Smart House Automated System}

The system demonstrates a Smart House controlled by a PLC. The system has three operation modes, namely, manual mode, energy saving mode, and security mode. In manual mode, the user can turn devices on or off as desired. In energy saving mode, the system can automatically turn on/off devices based on pre-determined operation rules; this is very useful in a large house. In secure mode, the system turns on an alarm and locks doors and windows when it detects an intrusion. Figure 6 shows the smart house system.

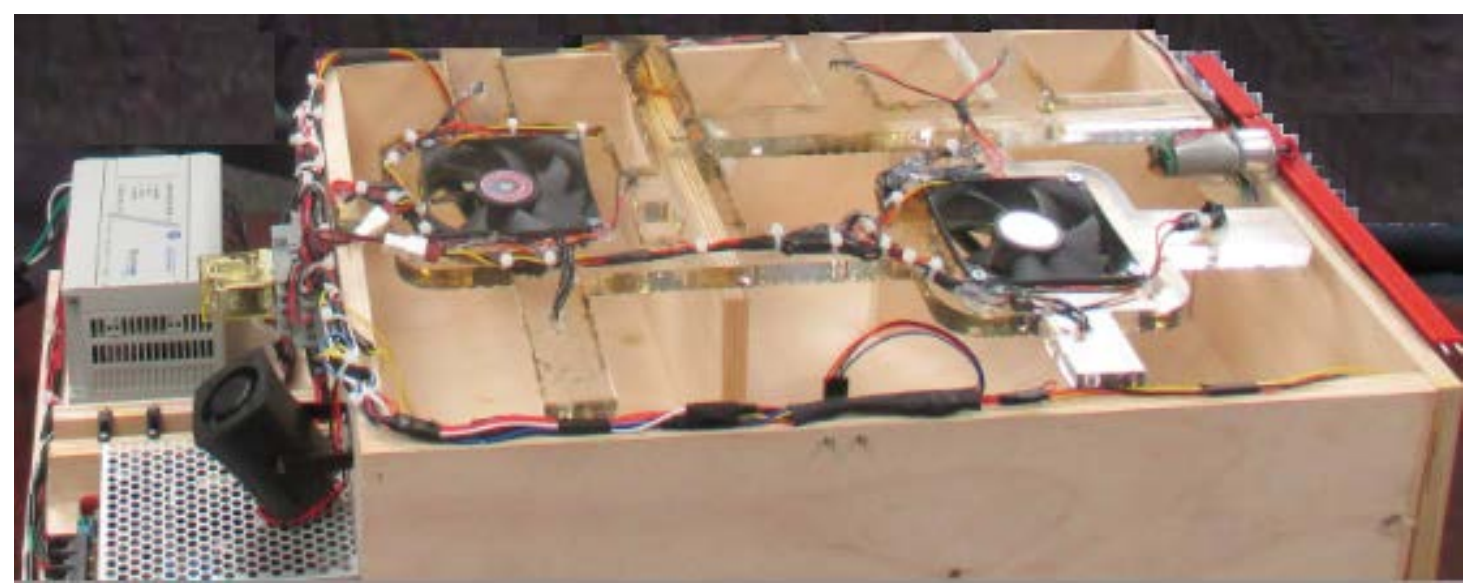

Figure 6. Overall Automated System of Smart House Application.

\section{Automated Sub-arc Welding System}

This system automates the sub-arc welding processing by using robotics and rotating and unloading stations. An entire gantry robot system and station were built from scratch using wood. All these components are controlled and synchronized by a programmable logic controller. Figure 7 shows the automated system. 


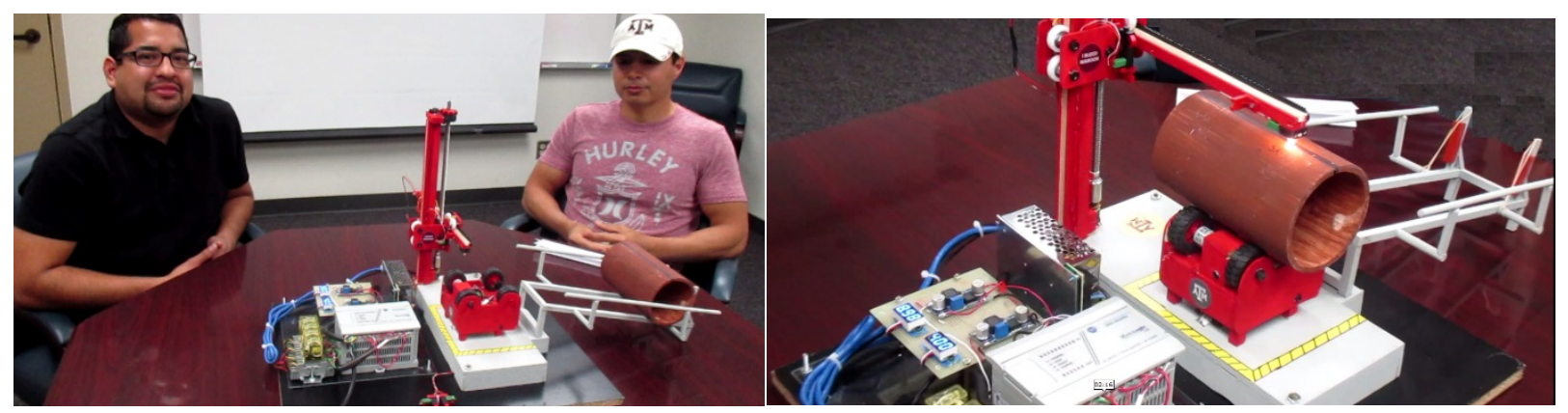

Figure 7. Overall Automated System for Sub-Arc Welding and System in Action.

\section{Evaluation}

At the end of the semester, students completed an online opinion survey rating various aspects of their experience of building Portable PLC with automated system. The survey used a 7 point Likert scale (1=strongly disagree; $7=$ strongly agree). The mean responses to the survey questions are shown in the figure below (Figure 8). Student ratings were very positive for all items (min 6.2, max 6.5). In general, students felt that building automated systems helped them to understand how PLC and sensors work. Also, they learned how to design, build, interface, program and troubleshoot an automated system and the hands-on experience helped them to visualize the process. They felt that building an automated system was a useful exercise and wanted to have more hands-on projects like this. 


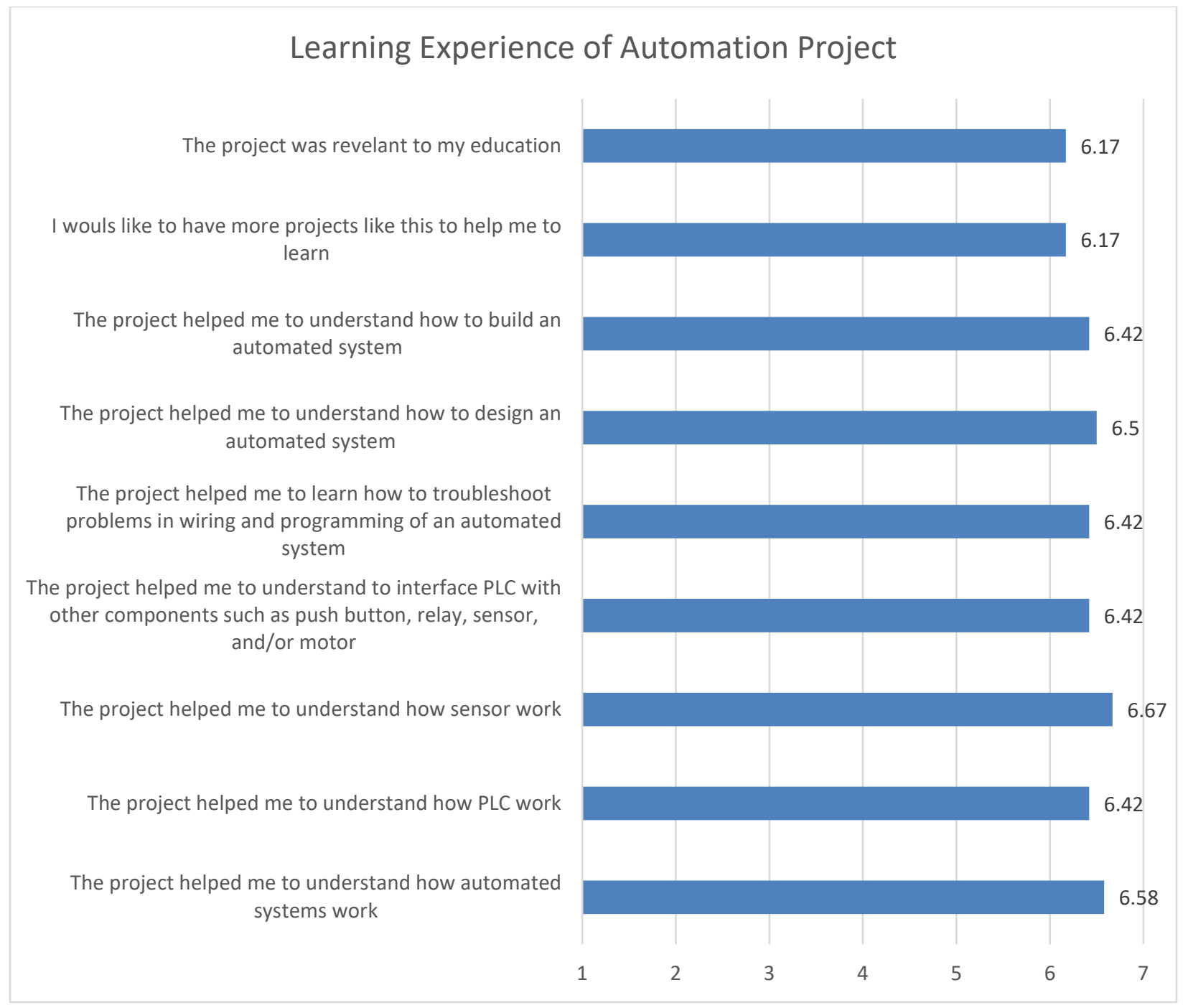

Figure 8. Mean responses to opinion survey questions.

\section{Student Comments}

In students' responses to the question “The most helpful thing about this project has been:” a common theme was that the students felt that project helped them to better grasp wiring and programming of an automated system after the subjects were covered in the class. A few stated that the project helped them to visualize course materials and to integrate the lectures with reallife learning experience. Below are their responses:

- Learn applicable solutions to real world problems.

- The wiring portion of the project was very useful to know. at the beginning of the project it was difficult to understand how wiring works. now that all wiring is complete I am more confident in my skills

- The hands on work, coding it by ourselves, making our own design and TA input when we had questions. 
- I found this project to be most helpful with learning wiring and how to apply it. This also became useful when studying for the exam.

- Doing actual hands on work to help understand the complexity of automated systems.

- Setting up the wiring diagram and getting it checked by our TA and our professor was very helpful to my understanding, as well as being able to troubleshoot problems with some assistance.

- Was wiring and programming the PLC. Everything we learned in class we were able to apply to our project.

- It helped bring all the different lessons of the class together for a better understanding. Actually getting to wire the PLC and all the components was better than any lesson I could have learned in class.

- The most helpful aspect of this project was physically wiring all the components. Before completing this I struggled with grasping the concepts of wiring. After completing the wiring of the project I was more confident.

In students' responses to the question "This project could be improved by:" common themes were 1) clear goals and deliverables in the beginning class; 2) larger work space for wiring; and $3)$ the entire class should work on the projects. The comments are below:

- Providing more specific milestones throughout the project

- Larger work spaces would certainly be beneficial, and covering the topic of relays and wiring at the same time as the project is being assigned would also be beneficial.

- Bigger work spaces for the wiring of the project. We were crowded in the lab.

- I think the class, should be working on the project and the lessons could be tough as stages of the project

\section{Conclusion and Future Directions}

The evaluation responses suggest that the automated system project and Portable PLC kits were well-received by students. Plans for the future include:

- Increase the number of projects and better understand when and how learning takes place.

- Understand knowledge gaps in building automated system and better synchronize lectures with project milestones.

- Provide better examples and samples of project deliverables at the beginning of the class.

- Build more automated system modules that allow students to see how different processes are automated and how sensors and actuators are incorporated into real-life applications.

- Educate graduating senior undergraduate students to become mentors for rising senior students who are working on building an automated system. Currently all mentoring is done by the instructor and TA, and additional mentors would help to alleviate bottlenecks while teams are designing and building of the automated system project

\section{Acknowledgements}

This material was supported by the National Science Foundation's Transforming Undergraduate Education in Science, Technology, Engineering, and Mathematics (TUES) Program (Award no. 
1246072). Any opinions, findings, and conclusions or recommendations expressed in this material are those of the author and do not necessarily reflect the views of the National Science Foundation.

\section{Bibliography}

[1] Bureau of the Census, Statistical brief: advanced manufacturing technology SB-13-90, U.S. Department of Commerce, Washington, D.C., 1990.

[2] U.S. Census Bureau. U.S. Trade in Advanced Technology Products - Flexible Manufacturing (Grouping 06) by Country (YTD DECEMBER 2015) - Monthly and Cumulative Data (in Millions US \$). Available online at: http://www.census.gov/foreign-trade/statistics/product/atp/2015/12/atpctry/atpg06.html (last accessed in July 2016).

[3] U.S. Census Bureau. U.S. Trade in Advanced Technology Products - Flexible Manufacturing (Grouping 06) by Country (YTD DECEMBER 2014) - Monthly and Cumulative Data (in Millions US \$). Available online at: http://www.census.gov/foreign-trade/statistics/product/atp/2014/12/atpctry/atpg06.html (last accessed in July 2016).

[4] Carnevale, A.P., et al. "Career Clusters: Forecasting Demand for High School through College Jobs, 20082018." Georgetown University Center on Education and the Workforce (2011). Available online at: http://www.nrccte.org/resources/publications/career-clusters-forecastingdemand- high-school-through-collegejobs-2008-2018 (last accessed in August 2016)

[5] U.S. Department of Labor Bureau of Labor Statistics, Occupational employment, job openings and worker characteristics - Table 1.7 Occupational employment and job openings data, projected 2014 and projected 2024, and worker characteristics, 2014. Available online at: http://www.bls.gov/emp/ep_table_107.htm

[6] Rich, M., “Factory Jobs Return, but Employers Find Skills Shortage,” The New York Times (July 1, 2010). Available online: http://www.nytimes.com/2010/07/02/business/economy/02manufacturing.html?emc=eta1 (last accessed on 8/4/2016).

[7] Hsieh, S. "Skill Sets Needed for Industrial Automation Careers" 2016 ASEE Annual Conference, June 26-29, New Orleans, LA.

[8] Web resource: https://www.linkedin.com/pulse/plc-vs-arduino-assem-zakaria

[9] Web resource: https://www.quora.com/Automation-Is-Arduino-replacing-programmable-logic-controller-inindustries

[10] Hsieh, S. and Hsieh, P.Y., "Web-based Modules for Programmable Logic Controller Education,” Computer Applications in Engineering Education, 13(4), Dec 2005, pp. 266-279.

[11] Hsieh, S. and Hsieh, P.Y., "An Integrated Virtual Learning System for Programmable Logic Controller," Journal of Engineering Education, 93(2), April, 2004.

[12] Hsieh, S. and Hsieh, P.Y., "Animations and Intelligent Tutoring Systems for Programmable Logic Controller Education,” International Journal of Engineering Education, 19(2), 2003.

[13] Hsieh, S. "Design and Preliminary Evaluation of Portable Kit for Programmable Logic Controller Education," 2015 ASEE Annual Conference, June 14-17, Seattle, WA.

[14] Hsieh, S. "Design and Evaluation of Sensor Module for Portable Programmable Logic Controller (PLC) Kit for Automated Control Education" 2016 ASEE Annual Conference, June 26-29, New Orleans, LA. 